University of Nebraska - Lincoln

DigitalCommons@University of Nebraska - Lincoln

2020

Communicated perspective-taking (CPT) and storylistening: Testing the impact of CPT in the context of friends telling stories of difficulty

Jody Koenig Kellas

Jonathan Baker

Megan Cardwell

Mackensie Minniear

Haley Kranstuber Hortsman

Follow this and additional works at: https://digitalcommons.unl.edu/commstudiespapers

Part of the Critical and Cultural Studies Commons, Gender, Race, Sexuality, and Ethnicity in Communication Commons, and the Other Communication Commons

This Article is brought to you for free and open access by the Communication Studies, Department of at DigitalCommons@University of Nebraska - Lincoln. It has been accepted for inclusion in Papers in Communication Studies by an authorized administrator of DigitalCommons@University of Nebraska - Lincoln. 


\title{
Communicated perspective-taking (CPT) and storylistening: Testing the impact of CPT in the context of friends telling sto- ries of difficulty
}

\author{
Jody Koenig Kellas, ${ }^{1}$ Jonathan Baker, ${ }^{2}$ Megan Cardwell, ${ }^{1}$ \\ Mackensie Minniear, ${ }^{1}$ and Haley Kranstuber Horstman ${ }^{3}$
}

\author{
1 University of Nebraska-Lincoln, USA \\ 2 University of South Florida, USA \\ 3 University of Missouri, USA \\ Corresponding author \\ Jody Koenig Kellas, Department of Communication Studies, University of Nebraska-Lincoln, \\ 365 Louise Pound Hall, Lincoln, NE 68588-0329, USA. Email: jkellas2@unl.edu \\ ORCID iDs \\ Jody Koenig Kellas https://orcid.org/0000-0003-4591-5354 \\ Megan Cardwell https://orcid.org/0000-0002-7283-1802 \\ Mackensie Minniear https://orcid.org/0000-0002-4993-2103
}

\begin{abstract}
Grounded in communicated narrative sense-making theory (CNSM), the purpose of the current study was to test the effects of storylisteners' communicated perspective taking (CPT) on storytellers' well-being and evaluations of storylisteners' communication skills in the context of telling stories about difficulty. Pairs of friends $(\boldsymbol{n}=37)$ engaged in a storytelling interaction in which one person told a story of a difficult life experience (DLE). Listeners' CPT was rated by observers using the Communicated Perspective-Taking Rating System (CPTRS) and tellers reported on listeners'
\end{abstract}

Published in Journal of Social and Personal Relationships, 2020, 23p.

doi:10.1177/0265407520955239

Copyright (c) 2020 Jody Koenig Kellas, Jonathan Baker, Megan Cardwell, Mackensie

Minniear, and Haley Kranstuber Horstman. Published by SAGE Publications. Used by

permission. 
behaviors and their own psychosocial health. Results indicate that observed CPT relates positively to tellers' perceptions of listeners' communication competence and CPT, and negatively to listeners' perceived face threat. Particularly important were the identity validation, agreement, and affective tone dimensions of the CPTRS. The links between observed CPT and communication skills were moderated by the degree to which the DLE was considered upsetting, significant, and based on how often the DLE story had been told. Despite previous research, observed CPT was not related to psychosocial health in the current study.

Keywords: Communicated narrative sense-making, communicated perspective taking, compassion, friends, listening, narrative, storytelling

In order to make sense of difficulty, trauma, and stress, people tell stories. Storytelling helps us make sense, gain a feeling of control, achieve catharsis, seek social support, and confirm our identities (Horstman et al., 2016; Koenig Kellas \& Trees, 2013; Weber et al., 1987). Research also suggests that the benefits of interpersonally disclosing difficulty depends on the responses of those who listen. Research on social support, for example, suggests that verbally person-centered responses predict greater perceptions of comforting for social support seekers (see High \& Solomon, 2016; Jones \& Guerrero, 2001) and that active listening in the context of "troubles talk" predicts improvements in emotional awareness and affect for the support seeker (Bodie et al., 2015).

In an initial exploration of the effects of storylistening, Koenig Kellas et al. (2015) examined the individual and interpersonal benefits of telling and listening to stories of difficulty among friends. Findings showed health benefits for tellers, decreases in listeners' positive and negative affect, and found that tellers' perceptions of their friends' listening and communication skills declined over time. Modeled after studies in the expressive writing paradigm (Frattaroli, 2006), Koenig Kellas et al.'s (2015) study tested the experimental effects of the opportunity to tell or listen to a difficult story over time (in comparison with a control group that talked about the events of the day). Left untested were the communication processes that characterize such storytelling interactions among friends that might further illuminate how storylistening impacts outcomes for storytellers trying to make sense of difficulty.

Trees and Koenig Kellas (2009) argue for the importance of examining the verbal and nonverbal behaviors relevant to sense-making and coping in the context of jointly telling stories of difficulty. Among the interactional sensemaking (ISM) behaviors they identified, including engagement, turn-taking, and jointly constructing coherence, communicated perspective-taking (CPT) has emerged consistently across studies as the strongest predictor of wellbeing for families and spouses during collaborative storytelling interactions 
(see Koenig Kellas et al., 2010; Trees \& Koenig Kellas, 2009). CPT is defined as the communicative manifestation of cognitive perspective-taking in which interactants not only "put themselves in each other's shoes" but also communicate their efforts to do so through attending to, understanding, and confirming another's perspective through verbal and nonverbal behaviors (Koenig Kellas et al., 2013).

In order to better understand the verbal and nonverbal behaviors that comprise communicated perspective-taking, Koenig Kellas et al. (2013) had spouses engage in an observational recall task and rate the degree to which their partners attended to, understood, and confirmed their perspective during each minute of a joint storytelling interaction about marital stress and then name specific behaviors that supported those ratings. The resulting set of verbal and nonverbal behaviors-(in)attentiveness, (ir)relevant contributions, (dis)- similarity, affective tone, space to tell (or not tell) the story, and (un)coordination-became the basis of an other-report-measure (see Koenig Kellas et al., 2015) and observational rating system (Koenig Kellas et al., 2017) of CPT. Because observed and reported CPT behaviors facilitate greater interactional sense-making and individual and relational well-being (see Koenig Kellas et al., 2010, 2017), CPT seems to be a particularly important form of compassionate, other-centered, dialogic listening in the context of interpersonal storytelling. Indeed, CNSM theory (Koenig Kellas, 2018) posits that higher levels of CPT will be positively related to individual and relational health (Proposition 5).

Grounded in CNSM Theory, the purpose of the current study is to extend Koenig Kellas et al.'s (2015) study and test the effects of storylisteners' CPT on storytellers' well-being and evaluations of storylisteners' communication skills in the context of telling stories about difficulty. Telling stories of stress to a friend may introduce social risks not present in writing about trauma (Koenig Kellas et al., 2015); therefore, the ability to take and communicate perspective-taking may be particularly important to ameliorating some of those risks through collaborative sense-making in the context of storytelling. Findings that further our understanding of good storylistening can and should inform future translational efforts to improve storylistening and relevant psychosocial and relational health outcomes for people coping with difficulty. The current study also provides an initial test of CNSM theory outside the context of family and marital relationships by examining how friends' CPT affects and reflects individual and relational health.

In what follows, we review literature on the benefits of storytelling, CPT, and listening in order to establish the argument that higher levels of CPT should result in tellers' improved well-being and perceptions of their listening friend. We then present the results of a study in which 37 pairs of friends engaged in a storytelling interaction about a traumatic issue experienced by the storyteller. 


\section{Rationale}

When people experience difficulty, such as stress, trauma, or emotional events, they often share their stories with other people, particularly if the event evoked negative emotions (Rimé et al., 1992). Interpersonal communication researchers seek to understand the implications and outcomes of such disclosure, particularly in close relationships. Early work on the "fever" model, for example, suggests that keeping in information, particularly stressful or emotional information, increases anxiety in individuals (Stiles, 1987). Therefore, disclosing information has a cathartic effect, such that when people disclose information, they often feel relieved (Stiles et al., 1992). Telling stories about difficulty can also help individuals make sense of their problems (Koenig Kellas, 2018) by encouraging tellers to emotionally purge, but also gain a sense of control over the events and increase understanding and self-esteem (Weber et al., 1987). Theories that focus on communicated sensemaking (Koenig Kellas, 2018; Koenig Kellas \& Kranstuber Horstman, 2015) examine the content, processes, and outcomes associated with communication processes that facilitate that ability to understand, process, and make sense of life's complexities.

Telling stories is a primary way in which humans employ, assign temporality to, and therefore cope and make sense of difficulty. Research within the expressive writing paradigm (see Frattaroli, 2006 for a review) has shown that writing about difficulty, for example, has significant physical and mental health benefits and these findings are theorized in terms of catharsis or emotional (dis)inhibition (Pennebaker, 1989), cognitive adaptation or sense-making (Niederhoffer \& Pennebaker, 2009), and social dynamics, or the benefits achieved from discussing interpersonal problems after writing about them (Pennebaker \& Graybeal, 2001). In short, talking or writing about traumatic stories has a variety of benefits for individuals. The majority of these benefits, however, have been theoretically based and empirically tested in terms of cognitive processes.

To address this, Koenig Kellas et al. (2015) studied whether telling a story of difficulty to a friend over time would have the same health benefits as expressive writing. In a study of 49 friend pairs, storytellers in the treatment group experienced a significant increase in negative affect after the first interaction (similar to expressive writing studies), but an overall decrease in negative affect across the course of two other storytelling interactions and at a 3-week follow-up. Interestingly, regardless of condition, storytellers' perceptions of their friends' communication competence, facework, and CPT decreased significantly over time. One possibility is that the experimental design modeled after expressive writing studies-telling a friend the same stories three times in 1 week-may have limited friends' abilities to listen 
effectively beyond the initial storytelling encounter. Thus, in the current study, we set out to test CNSM Theory's proposition 5 to better understand the link between listener CPT behaviors and storytellers' perceptions of the first storytelling interaction.

\section{Social support, effective listening, and CPT}

Ample research suggests that communicative responses are particularly important to coping with difficulty. For example, negative experiences following the disclosure of difficulty can lead to decreased relational, psychological, and physical health outcomes for both the discloser and person being disclosed to (Joseph et al., 2016). When friends perceive good social support from their conversational partners, they report more satisfaction with their friendships (Afifi et al., 2013). However, discrepancy in emotional support standards actually may increase rumination about the stressful event as well as the relationship itself (Joseph et al., 2016). Overall, the listener in any disclosure encounter bears a large responsibility in creating a positive conversational climate.

Research on emotional support, comforting communication, and listening substantiates this importance. The theory of constructivism (Delia et al., 1982) examines the ways in which people differ in their ability to rely on cognitive constructs (e.g., cognitive complexity) to produce adaptive, contextual, or person-centered messages. Research growing out of this tradition on verbal person-centeredness (VPC, Burleson, 1994), for example, uses scenarios or experimentally manipulated levels of support in messages from confederates to understand how others evaluate social support. VPC is defined as "the extent to which messages explicitly acknowledge, elaborate, legitimize, and contextualize the feelings and perspective of a distressed other (Burleson, 1994)" (Bodie \& Jones, 2012, p. 570). According to High and Dillard (2012), messages low in VPC deny the other person's feelings; moderate in VPC attempt to reframe the situation or reduce distress; and high in VPC recognize, legitimate, and help the other person elaborate on their feelings. Moreover, meta analyses show that high VPC positively predicts actual and perceived effectiveness (High \& Dillard, 2012). In short, supportive messages high in VPC are more effective than those low in VPC.

In a related program of research on the links between supportive communication and listening, Bodie et al. (2015), identified active listening as fundamental to evaluations of enacted social support, arguing that good support depends on good listening. They define active listening as "verbal [e.g., paraphrasing, reflecting feelings, asking questions] and nonverbal behaviors [e.g., immediacy behaviors such as head nods, eye contact, forward lean] that function to demonstrate attention, understanding, 
responsiveness, and empathy; to encourage continued expression of thought and feelings; and to aid in relational maintenance" (p. 153). The authors found, along with Bodie (2011), that verbal behaviors seemed to be more important in predicting positive evaluations of support providers than nonverbal behaviors.

CPT refers to the ability to not only put oneself in another's shoes, but also communicate that ability and therefore might be considered a type of person-centered communication (Delia et al., 1982). CPT focuses on the verbal (content) and nonverbal (behavioral) communication that contributes to collaborative sense-making and therefore provides a parsimonious conceptualization of other-centered interpersonal dialogue (see Stewart \& Koenig Kellas, 2020). CPT emerged inductively as a construct when participants were asked to identify the behaviors that made them feel their spouse was taking their perspective (Koenig Kellas et al., 2013). Unlike VPC which focuses on explicit messages, CPT behaviors focus on verbal and nonverbal behaviors across an interaction and extends beyond the context of social support.

CPT derives from research on joint or collaborative storytelling with a focus on meaning-making that also overlaps with more dialogic definitions of listening and collaborative communication, rather than the cognitive constructs of constructivism. Dialogic approaches to interpersonal communication focus on the co-construction of meaning (Stewart \& Koenig Kellas, 2020). Dialogic listening, for example, has been defined by Stewart (2014) as listening whose purpose is the collaborative construction of meaning among conversational partners. Rehling (2008) refers to dialogic listening as compassionate listening, or a collaboration to understand another's suffering, emphasizing the centrality of connectedness, openness to another, and the desire to alleviate another's isolation, loneliness, and suffering through this collaborative approach.

We argue that communicated perspective-taking can be conceptualized as one form of compassionate communication at the intersections of empathic, active, dialogic, and compassionate listening. CPT focuses on nonverbal immediacy, verbal responses, and other-centered orientation, and has manifested in research as a compassionate response to stories of difficulty (see Horstman et al., 2016; Koenig Kellas et al., 2010). Beyond the verbal and nonverbal behaviors that signal effective listening, individuals recognize CPT through communication behaviors that convey mutual understanding, meaning-making, confirmation of identity, and coordination with the other person (see Koenig Kellas et al., 2013). We grounded the current study in CNSM (Koenig Kellas, 2018; Koenig Kellas \& Kranstuber Horstman, 2015) based on CPT's centrality to the theory. 


\section{CNSM theory}

CNSM Theory (Koenig Kellas, 2018; Koenig Kellas \& Kranstuber Horstman, 2015) focuses on the links between storytelling, health, and well-being across interpersonal and relational contexts. The theory is organized around three heuristics: retrospective storytelling, interactional storytelling, and translational storytelling. Broadly, retrospective storytelling posits that the stories we hear and tell reveal individual, relational, and intergenerational values and beliefs. Interactional storytelling is concerned with the process of storytelling between individuals and proposes that health and well-being outcomes are linked with interactional sense making including CPT. Finally, translational storytelling is the process of using narrative theorizing, inquiry, and empirical results to create interventions, programs, or resources that positively impact the health of target populations. In the current study, we focused primarily on the interactional storytelling heuristic.

Interactional storytelling. Koenig Kellas (2018) contends that Interactional Storytelling is at the heart of CNSM's commitment to narrative as communication, "because it focuses explicitly on the communicative processes that characterize storytelling" (p. 66). At the center of the interactional storytelling heuristic is the proposition that ISM predicts greater levels of narrative sense-making and individual and relational well-being. ISM behaviors include engagement, turn-taking, and jointly constructing coherence, and CPT (see Koenig Kellas \& Trees, 2005).

CPT. Research has identified links between CPT and family functioning, perceptions of family supportiveness (Trees \& Koenig Kellas, 2009), the positivity of one's own narrative framing (Horstman et al., 2016), and husbands' mental health (Koenig Kellas et al., 2010). This research informed the creation of an other-report survey measure of CPT (OCPT) which has been used to assess friends' perceptions of each other during storytelling interactions (Koenig Kellas et al., 2015) and spouse's marital satisfaction and affect in the context of miscarriage (Horstman \& Holman, 2017). Finally, The Communicated Perspective-Taking Rating System (CPTRS, Koenig Kellas et al., 2017) was developed for observational rating of CPT behaviors including attentiveness, agreement, affective tone, validating identity, creating space to talk, and global ratings of CPT attentiveness and confirmation. A study of married couples' conflict interactions using the CPTRS found that wives' CPT predicted husbands' marital satisfaction and husbands' CPT similarly predicted satisfaction for wives (Koenig Kellas et al., 2017).

Clearly, previous research indicates that CPT behaviors positively predict individual and relational outcomes in family and marital relationships. 
Despite this, we know little about how CPT operates in other relationships. Friendships are an integral source of social support, particularly in times of transition (such as emerging adulthood), stress, and difficulty. Because of the previous research on the relational (e.g., relational satisfaction) benefits of CPT, CPT processes likely represent an important set of skills for storylisteners trying to help their friends make sense of difficulty. In the current study, we were interested in employing the CPTRS to understand how CPT operates in the context of storylistening to impact relational evaluations. In doing so, we go a step beyond Koenig Kellas et al. (2015) to investigate not only if telling a story has benefits for tellers, but to also examine how storylistening impacts interpersonal perceptions. Because most research to date suggests a positive relationship between CPT and relational outcomes, we predicted that CPT would be seen as a positive form of storylistening as operationalized by tellers' perceptions of how well listeners communicated during the storytelling interaction.

Tellers' perceptions of listeners' communication were measured by assessing their perception of friends' communication competence, CPT, and face threatening behaviors. Communication competence represents an overarching evaluation of communicators' skills (Spitzberg, 1994) and therefore serves as an appropriate assessment of friends' listening abilities. As a central construct in the current study, we were especially interested in understanding how tellers rated their friends' communicated perspective-taking behaviors. Therefore, in addition to assessing observers' ratings of CPT, we also asked storytellers to rate the quality of storylisteners' CPT following the interaction. Finally, because of the potentially face threatening nature of telling a story of difficulty, we reasoned that observed levels of CPT would also result in lower levels of perceived face threat (Cupach \& Carson, 2002). Thus, we hypothesized:

H1: Higher levels of CPT will predict higher levels of storytellers' perception of their friend's (a) communication competence, (b) CPT, and lower levels of (c) face threatening behaviors immediately following a storytelling conversation about difficulty.

Because the CPTRS is a relatively new observational rating system, we also wanted to conduct follow-up exploratory analyses to examine how the various elements of the CPTRS operated in relation to friends' assessments of each other's communication skills. Bodie (2011) and Bodie et al. (2015), for example, found that verbal listening behaviors were more important than nonverbal behaviors (e.g., nonverbal immediacy) in predicting assessments of listening effectiveness and social support provision, respectively. It is possible that certain aspects of the CPTRS will be more important in predicting tellers' perceptions of their friends CPT, communication competence, and 
perceived face threat. Indeed, in the first test of the CPTRS, Koenig Kellas et al. (2017) reasoned, "It may also be that certain dimensions of CPT are more important than others in explaining" outcomes (p. 199). Moreover, Koenig Kellas et al. (2013) found that husbands' ratings of their wife's CPT was predicted by negative tone, disagreement, and the perception that wives were constraining their version of the story; although wives' ratings of husbands' CPT was also related to observational ratings of constraint and disagreement, wives' perceptions of their husbands' irrelevant contributions and inattentiveness were also significantly related to their ratings of their spouse's CPT. These differences across dimensions in CPT and listening research prompted the following exploratory research question:

RQ1: How do certain elements of the CPTRS relate to storytellers' perception of the listener's (a) communication competence, (b) CPT, and (c) face threatening behaviors?

In addition to explaining the links between observed and other-reported communication skills, in the current study, we were also interested in further testing CNSM theory which supports links between storytelling and wellbeing. Based on the previously reviewed research that identifies CPT as a process central to interactional sense-making in storytelling communication and the overwhelmingly positive individual and relational benefits of CPT (see Koenig Kellas et al., 2017 for a review), the fifth proposition of CNSM states "Higher levels of communicated perspective-taking predict higher levels of individual and relational health and well-being" (Koenig Kellas, 2018, p. 67). Thus, we hypothesized links between listeners' observed CPT and tellers' psychosocial health. Following previous expressive writing (see Frattaroli, 2006) and CNSM studies (see Koenig Kellas et al., 2010), we assessed psychosocial health in terms of affect, life satisfaction, and mental health. Although telling (Koenig Kellas et al., 2015) or writing (Frattaroli, 2006) stories of difficulty can result in immediate levels of diminished psychosocial health (despite its long-term benefits), we reasoned that better CPT might ameliorate some of the negativity possible when telling the story of difficulty to a friend for the first time. Therefore, we hypothesized:

H2: Higher levels of CPT will predict higher levels of storytellers' (a) mental health, (b) life satisfaction, (c) positive affect and lower levels of storytellers' (d) negative affect immediately following a storytelling conversation about difficulty.

Finally, CNSM theory also highlights links between storytelling content and context and individual and relational health. For example, Kranstuber and Koenig Kellas (2011) found that ratings of the salience of elements of 
adult adoptees' adoption stories predicted assessments of their self-concept. In their original work explicating the links between storytelling and wellbeing, Lyubomirsky et al. (2006) used the Life Experience Questionnaire (LEQ) to generate stories and rate story characteristics, including level of upset, significance, recency, resolvability, and times told between positive and negative stories. They then used these characteristics to rule out differences between experimental conditions. Across three experiments, Lyubomirsky et al. also found that participant well-being differed based on story valence, such that writing or talking about a negative story improved participants' self-reported life satisfaction and mental health; the opposite was true when participants wrote or talked about positive stories. They reasoned that multiple tellings of a negative story can lead to sense-making and catharsis, whereas the repeated tellings of a positive story can lead to over-analysis. Research in the expressive writing paradigm typically has participants talk about highly upsetting or traumatic events and has shown benefits of making sense of these significant difficulties (see Frattaroli, 2006). Thus, we would expect the nature of the story to interact with listener behavior to impact tellers' well-being and perceptions of the interaction. For example, friends who tell extremely upsetting or significant stories might place even more weight on the ways their friends listen and respond, thereby affecting the relationship between observed CPT and perceptions of friends' communication skill. It may also be that CPT matters more to well-being when the story has been told infrequently, thus magnifying the benefits of catharsis. In order to test these assumptions and bolster evidence for CNSM theory's proposed link between storytelling content, process, and well-being, we examined the degree to which tellers' perceptions of their story's significance, level of upset, and the number of times told moderated the relationship between observed CPT and tellers' individual and relational well-being:

RQ2: Does the nature of the story (upset, significance, times told) moderate the relationship between observed CPT by listeners and tellers' (a) psychosocial health and (b) perceptions of their friends' communication skills?

\section{Method}

The current study is part of Koenig Kellas et al.'s (2015) study on the outcomes associated with storytelling and storylistening over time. Because the current study focused on the links between CPT and outcomes for tellers', we focused the current analysis on trained observers' CPT ratings of the videotaped interactions between friends in the treatment group (see 
procedure below) and tellers' self-reports of mental health and perception of the listeners' communication behavior.

\section{Participants}

After receiving IRB approval, participants were recruited through communication courses at a large Midwestern university. Students were offered extra credit in exchange for participating in the study. Participants in the current analysis included 37 pairs of emerging adult college student friends $\left(M_{\text {age }}=20.49, S D=2.22, N=74\right)$. Although six did not report on sex, approximately half the sample was male $(n=35,51.5 \%)$ and half was female ( $n=33,48.5 \%)$. Seven were mixed-sex friend pairs (19\%) and the rest were same-sex pairs. Of those who reported on ethnicity, 49 participants were White (66.2\%), eight were Asian (10.8\%), one was African American, one was Hispanic, and one was Native American (1.4\% respectively), and nine reported Other (12.2\%). Friendship length averaged 38.51 months $(S D=$ $43.90)$, and friends reported moderate levels of closeness $(M=3.70, S D=$ 1.21 on a 5 -point scale).

\section{Procedures}

Interested participants contacted a member of the research team and solicited a willing friend to participate in the study with them. In the larger study, the experimental design included a treatment (storytelling condition) and control group and three phases: prestudy $(24 \mathrm{hr}$ prior to the first lab visit), storytelling interactions (including three 10-min interactions in the lab over the course of 1 week followed by survey measures), and poststudy (3 weeks later). Participants were randomly assigned to the role of storyteller or listener. In the current study, because we were interested in the ways in which CPT operated in storytelling interactions, we limited our analysis to the treatment group on the first day of storytelling interactions. Because the experimental design, modeled after writing studies (see Frattaroli, 2006), may have created a less natural environment (e.g., tellers were instructed to tell the same story 3 days in a row) thereby compromising listeners' ability to communicate spontaneously, we chose to focus on the first time they heard the story in order to understand how their CPT predicted tellers' reactions. Thus, in the remainder of this study, we describe the methods and results related to the 37 pairs in the treatment group and their surveys and interactions following the first storytelling interaction.

Pre-study. Before participating in the study, a research assistant e-mailed the participants a pre-interaction survey, including informed consent, 
demographic data, and measures of friendship length, physical and mental health, life satisfaction, and positive and negative affect. Participants were asked to respond within $24 \mathrm{hr}$ prior to their appointment.

Storytelling interaction. On the first day in the lab, participants were welcomed, randomly assigned to the role of listener or teller and separated to complete questionnaires. Listeners completed measures not relevant to the current study. Storytellers filled out measures not relevant to the current study along with the Life Experience Questionnaire (LEQ, Lyubomirsky et al., 2006) to determine a difficult life experience (DLE) that would be the topic of their storytelling. Participants were then brought together. Storytellers were instructed to tell their story using instructions adapted from Lyubomirsky et al. Listeners were instructed to interact as they normally would. Specifically, listeners were instructed:

As your friend tells the story, I would like you to listen and interact as you normally would if (the storyteller) were to tell you a story such as this. In other words, there is no right or wrong way to listen and you are free to interact, talk, ask questions, interject, or keep quiet, etc. The point is for you to listen/interact how you normally would if he or she was telling this story in a place where you typically get together.

The researcher then left the room and the pair interacted for $10 \mathrm{~min}$. After the interaction, participants completed measures identical to the pre-study survey, as well as measures of their friends' interpersonal communication ability, including perceived face threat (Cupach \& Carson, 2002), communication competence (Guerrero, 1994), and communicated perspective-taking (Koenig Kellas et al., 2015).

\section{Measures}

Life Experience Questionnaire (LEQ). The LEQ was adapted from Lyubomirsky et al. (2006). Specifically, we asked participants to identify three difficult life experiences (DLE) and then to rate each one on a series of 10-point Likert-type measures which assessed the degree to which the DLE event was upsetting ( 1 = not upsetting, 10 = extremely upsetting), resolvable ( 1 = not easily resolvable, $10=$ easily resolvable), significant $(1=$ not at all significant, 10 = very significant), and the amount of time the teller had already spent discussing the topic with others $(1=$ none, $10=$ a lot). Participants also identified the events' recency. After completing the LEQ, the researcher worked with the teller to select the story topic that was the most recent, 
significant, upsetting and least often talked about. In the current study, story topics included problems with school $(n=11)$, death of a loved one $(n=10)$, family and relational difficulties or dissolution $(n=7)$, own or others' mental or substance abuse problems $(n=6)$, and moving $(n=3)$. Topics were rated by tellers as moderately upsetting $(M=5.92, S D=2.36)$, very significant ( $M$ $=8.08, S D=1.50)$, and somewhat resolvable $(M=4.65, S D=2.62)$. Tellers reported talking about events that happened an average of months ago (Median $=17.00 ; S D=35.73$ ) and that they had talked about a moderate amount $(M=4.22, S D=1.90)$.

Positive and negative affect. Positive and negative affect were measured with items adapted from the Positive and Negative Affect Schedule (PANAS, Watson et al., 1988). Participants indicated on a 5-point Likert scale ranging from "Very slightly or not at all (1)" to "Extremely (5)" how much certain words described them at the present moment (e.g., Interested, Distressed, Excited). Positive and negative affect were each indicated by 10 emotions, respectively. Composites were formed by summing the scores for positive affect such that higher scores indicate higher levels of each (see Table 1 for descriptive statistics and reliabilities for all study variables).

Life satisfaction. Satisfaction with life was measured with Deiner et al.'s (1985) scale. Participants filled out 5 items on a 7-point Likert-type scale ranging from "Strongly disagree (1)" to "Strongly Agree (7)", with higher scores indicating higher levels of the construct (e.g., "In most ways my life close to ideal," "The conditions of my life are excellent").

Mental health. Mental health symptoms were measured with nine items adapted from Stewart et al.'s (1992) MOS Health Survey. Participants were asked to think about how they were feeling at the time of the survey and rate items (e.g., "I feel full of pep," "I feel downhearted and blue") on a 6-point Likert-type scale ranging from 1 "not at all" to 6 "extremely." Five items were reverse coded such that higher scores indicated better mental health.

Other communicated perspective-taking (OCPT). Tellers' perception of the listeners' CPT was measured with the OCPT scale (Koenig Kellas et al., 2015). The OCPT has been used reliably in research about spouses' perception of miscarriage (Horstman \& Holman, 2017, a = .93-.95). Participants filled out the 19-item, 5-point Likert-type scale, ranging from "Strongly disagree (1)" to "Strongly agree (5)" with higher scores indicating higher levels of the construct (e.g., "My friend was attentive to me during our conversations," "My friend gave me plenty of space to tell my story"). Composites were calculated by averaging all 19 items after 6 items were reverse coded. 
Perceived communication competence. Tellers' perceptions of listeners' communication competence were measured using Guerrero's (1994) measure which consists of 6 items (e.g., "My friend was a good communicator," "My friend was a good listener") rated on a 5-point Likert-type scale (1 = strongly disagree, 5 = strongly agree). Two items were reverse coded and all 6 items were averaged together to form a composite score such that higher scores indicate higher levels of perceived communication competence.

Perceived face threat. Perceived face threat was measured with items adapted from Cupach and Carson (2002) including 14 items on a 5-point Likert-type scale ranging from "Strongly disagree (1)" to "Strongly agree (5). Example items include "During the interaction my friend was polite," and "During the interaction my friend made me look bad." Four items in the measure were reverse-coded, such that higher scores indicated higher levels of perceived face threat. Items were averaged to create a composite score.

Communicated perspective-taking rating system (CPTRS). Observed levels of listeners' CPT was rated by trained observers using the Communicated Perspective-Taking Rating System (CPTRS). The CPTRS was developed by Koenig Kellas et al. (2017) as a reliable observational system used to measure CPT in interactions. The CPTRS rates seven constructs of behavior on 5-point Likert-type scales ( 1 = low, strong lack of perspective-taking behaviors or strong demonstration of negative behaviors; 5 = high, strong degree of perspective-taking behavior and no negative behaviors).

Conversational (in)attentiveness includes verbal and nonverbal behaviors that signal (dis)engagement in the interaction (e.g., eye contact, nodding; tuning out). Creating space to talk is the degree to which partners share the floor and encourage each-other to share their opinions (e.g., waiting for the other person to finish; interrupting). (Dis)-Agreement/(mis)understanding refers to the communication of (dis)similarity, (in)consistency in perspective, style, or understanding (e.g., agreeing; correcting the other person). Affective tone refers to certain behaviors that set the tone, tenor, or mood of the interaction (e.g., showing kindness; being sarcastic). Validating partner identity is the extent to which partners communicate (in) validation and acceptance of their partner as a person (e.g., verbally validating the other person's actions; undermining the person's view of self). Global attentiveness to others' perspectives measures the overall presence of perspective-taking and partners' integration of each-other's perspectives into a meaningful discussion of the difficulty. Global confirmation of others' perspectives is the degree to which the overall interaction consists of confirming perspectives of the other (see Koenig Kellas et al., 2017 for a full description of each construct). 
Table 1. Descriptive statistics for study variables.

\begin{tabular}{lrrr} 
Variable name & $M$ & $S D$ & $\alpha$ \\
\hline 1. Positive Affect & 29.14 & 7.55 & .93 \\
2. Negative Affect & 17.09 & 4.57 & .78 \\
3. Life Satisfaction & 25.14 & 6.72 & .88 \\
4. Mental Health & 4.35 & .62 & .79 \\
5. OCPT & 4.41 & .35 & .80 \\
6. OCC & 4.20 & .46 & .80 \\
7. PFT & 1.59 & .31 & .67 \\
8. CPTRS Average & 4.09 & .56 & .94 \\
& & & ICCs \\
9. CPTRS Attentiveness & 4.48 & .47 & .73 \\
10. CPTRS Create Space & 4.25 & .65 & .83 \\
11. CPTRS Agreement & 4.26 & .64 & .85 \\
12. CPTRS Identity & 3.65 & .71 & .81 \\
13. CPTRS Affective Tone & 3.98 & .72 & .83 \\
14. CPTRS Global Attentiveness & 4.09 & .66 & .88 \\
15. CPTRS Global Confirmation & 3.91 & .68 & .81 \\
\hline
\end{tabular}

Note: Communicated perspective-taking rating system (CPTRS), other-report communicated perspective-taking (OCPT), other-report communication competence (OCC), perceived face threat (PFT), intraclass correlation coefficient (ICC).

Three raters were trained on the CPTRS for approximately 8 weeks during which they practiced observing and rating interactions from the second wave of data not used in the current study. Per CPTRS training manual guidelines, the entire interaction was rated to provide a global rating of each of the seven constructs across the $10 \mathrm{~min}$. Raters took notes on a rating sheet while watching each interaction to ensure fidelity across the interaction. After establishing initial levels of reliability, raters rated interactions in batches of 10 checking reliability to guard against coder drift. All seven constructs were rated reliably, and raters' scores were averaged across each of the seven dimensions (see Table 1). Based on CPTRS guidelines, all seven composite scores were averaged to create an overall observational CPT score (see Table 1). Higher scores reflect higher levels of observed listener CPT.

\section{Results}

Hypothesis 1 predicted that higher levels of CPT would predict higher levels of tellers' perceptions of their friend's communication competence and CPT, and lower levels of their friend's face threatening behaviors immediately 
following a storytelling conversation about difficulty. Results show that higher levels of observed CPT were related to higher levels of tellers' perceptions of friends' communication competence $\left[r(36)=.35, p<.05, r^{2}=.12\right]$, CPT, $\left[r(36)=.41, p<.01, r^{2}=.17\right]$, and lower levels of their friend's face threatening behaviors $\left[r(36)=-.42, p<.01, r^{2}=.18\right]$. Thus, $\mathrm{H} 1$ was supported.

Although $\mathrm{H} 1$ reflects a main analysis of the CPTRS on tellers' evaluations of listeners' behaviors, we engaged in follow-up exploratory analyses of the different dimensions of the CPTRS based on research by Koenig Kellas and colleagues $(2017,2013)$ that suggests the need to further explore the nuance of this relatively new set of constructs. RQ1, therefore, asked how elements of the CPTRS related storytellers' perceptions of their friends' communication skills. Pearson product moment correlations (see Table 2) indicate that the CPTRS dimensions of agreement, identity, and affective tone all relate significantly and positively to tellers' perceptions of their friends' communication competence, CPT, and negatively to perceived face threat. These were, in fact, the only three CPTRS dimensions that related to perceptions of communication competence. Observed global attentiveness and global confirmation were significantly related to both tellers' perceptions of their friends' CPT and face threat. Finally, the observational rating of the degree to which listeners' created space also negatively predicted perceived face threat. Interestingly, the CPTRS dimension of attentiveness

Table 2. Pearson's correlations for study variables.

\begin{tabular}{|c|c|c|c|c|c|c|c|c|c|c|c|c|c|c|c|}
\hline Variable name & 1. & 2. & 3. & 4. & 5. & 6. & 7. & 8. & 9. & 10. & 11. & 12. & 13. & 14. & 15. \\
\hline 1. Positive Affect & 1.00 & -.15 & -.09 & $.29 *$ & .07 & $.32^{*}$ & -.08 & -.18 & -.14 & .02 & .26 & .15 & .25 & .16 & .27 \\
\hline 2. Negative Affect & & 1.00 & -.12 & $-.30 *$ & -.11 & .04 & .02 & -.16 & -.07 & .02 & -.20 & -.07 & -.22 & -.21 & -.21 \\
\hline 3. Life Satisfaction & & & 1.00 & $.29^{*}$ & .18 & .17 & -.23 & -.18 & .14 & .17 & .25 & .09 & .17 & .12 & .12 \\
\hline 4. Mental Health & & & & 1.00 & -.00 & .18 & .06 & -.06 & -.12 & -.17 & -.04 & -.04 & -.02 & -.01 & -.05 \\
\hline 5. OCPT Post-Interaction & & & & & 1.00 & $.637^{* *}$ & $\star-.591$ & $.41^{\star *}$ & .26 & .26 & $.32^{*}$ & $.48^{* *}$ & $.45^{\star *}$ & $.32^{*}$ & $.32^{*}$ \\
\hline 6. OCC Post-Interaction & & & & & & 1.00 & $-.465^{\star *}$ & * $.35^{\star}$ & .13 & .15 & $.38^{*}$ & $.44^{* *}$ & $.41^{* *}$ & .28 & .26 \\
\hline 7. PFT Post-Interaction & & & & & & & 1.00 & $-.42^{\star *}$ & -.270 & $-.37^{*}$ & $-.40^{\star *}$ & $-.45^{\star *}$ & $-.42^{\star *}$ & $-.31^{*}$ & $-.32^{*}$ \\
\hline 8. CPTRS Average & & & & & & & & 1.00 & $.68^{* *}$ & $.76^{\star *}$ & $.89^{\star *}$ & $.81^{\star *}$ & $.94^{\star *}$ & $.95^{* *}$ & $.94^{\star *}$ \\
\hline 9. CPTRS Attentiveness & & & & & & & & & 1.00 & $.42^{* *}$ & $.62^{\star *}$ & $.62^{\star *}$ & $.38^{\star *}$ & $.65^{* *}$ & $.54^{\star *}$ \\
\hline 10. CPTRS Create Space & & & & & & & & & & 1.00 & $.55^{\star \star}$ & $.64^{\star *}$ & $.52^{\star *}$ & $.72^{\star *}$ & $.66^{\star *}$ \\
\hline 11. CPTRS Agreement & & & & & & & & & & & 1.00 & $.82^{\star *}$ & $.68^{\star *}$ & $.82^{* *}$ & $.83^{\star *}$ \\
\hline 12. CPTRS Identity & & & & & & & & & & & & 1.00 & $.72^{\star *}$ & $.86^{\star *}$ & $.90^{\star *}$ \\
\hline 13. CPTRS Affective Tone & & & & & & & & & & & & & 1.00 & $.71^{\star \star}$ & $.75^{\star \star}$ \\
\hline 14. CPTRS Global Attenti & eness & & & & & & & & & & & & & 1.00 & $.88^{* *}$ \\
\hline 15. CPTRS Global Confirr & ation & & & & & & & & & & & & & & 1.00 \\
\hline
\end{tabular}

Note: Communicated perspective-taking rating system (CPTRS), other-report communicated perspective-taking (OCPT), other-report communication competence (OCC), perceived face threat (PFT).

${ }^{*} P<.05$

${ }^{* *} p<.01$ 
was not significantly related to any of the dependent variables. In summary, the strongest significant predictors were agreement, identity, and affective tone, and perceived face threat and CPT were sensitive to more dimensions of the CPTRS than were perceptions of communication competence.

Hypothesis 2 predicted that higher levels of CPT would predict higher levels of psychosocial well-being as operationalized by mental health, life satisfaction, positive and negative affect immediately following the storytelling interaction. As illustrated in Table 2, results indicate that higher levels of CPT were not related to teller's psychosocial well-being following the storytelling interaction. Thus, $\mathrm{H} 2$ was not supported.

Finally, RQ2 asked if tellers' ratings of the nature of the story they told moderated the relationship between observed CPT and (a) psychosocial health and (b) perceptions of their friends' communication skills. Because none of the psychosocial health variables were significantly related to observed CPT, moderation models for positive and negative affect, life satisfaction, and mental health were not run. In order to test the interaction on friends' communication skills, a series of separate moderation models with observed CPT as the independent variable, tellers' perceptions of listeners' communication competence, CPT, and face threat as the dependent variables, and the degree to which tellers rated their story topics as upsetting, significant, and often told as the moderators were run through the PROCESS macro for SPSS (Hayes, 2013). Variables were mean-centered before interaction terms were created. Significant models emerged for perceived face threat and trends emerged for perceptions of friends' communication competence. ${ }^{1}$ No significant models emerged for perceptions of friends' CPT.

First, for perceived face threat, moderation analyses indicated significant interaction effects for the product of observed CPT and the difficult life experience (DLE) level of upset, which added 17\% $(F=7.84, p<.01)$ explained variance to the model. Simple slopes were computed using PROCESS (Model 1, Hayes, 2013) when DLE upset was one standard deviation above or below the mean $(M=5.92, S D=2.36)$. Findings suggest that when DLE upset was high and moderate, the strength of the negative relationship between observed CPT and perceived face threat was stronger $(-1 S D=-.03, p>$ $.05, M=-.25, p<.05,+1 S D=-.48, p<.01)$. Similar patterns were found for perceived face threat based on the interaction between observed CPT and the significance of the DLE (added 10\% explained variance to the model, $F=4.36, p=.01, M=8.08, S D=1.50 ;-1 S D=.01, p>.05, M=-.22, p<$ $.05,+1 S D=-.45, p<.01)$ and the interaction between observed CPT and the number of times the DLE has been talked about (added $16 \%$ explained variance to the model, $F=5.57, p<.01, M=4.22, S D=1.90 ;-1 S D=.00$, $p>.05, M=-.29, p<.01,+1 S D=-.59, p<.001)$. These results-depicted in Figure 1-indicate a negative relationship between observed CPT and 

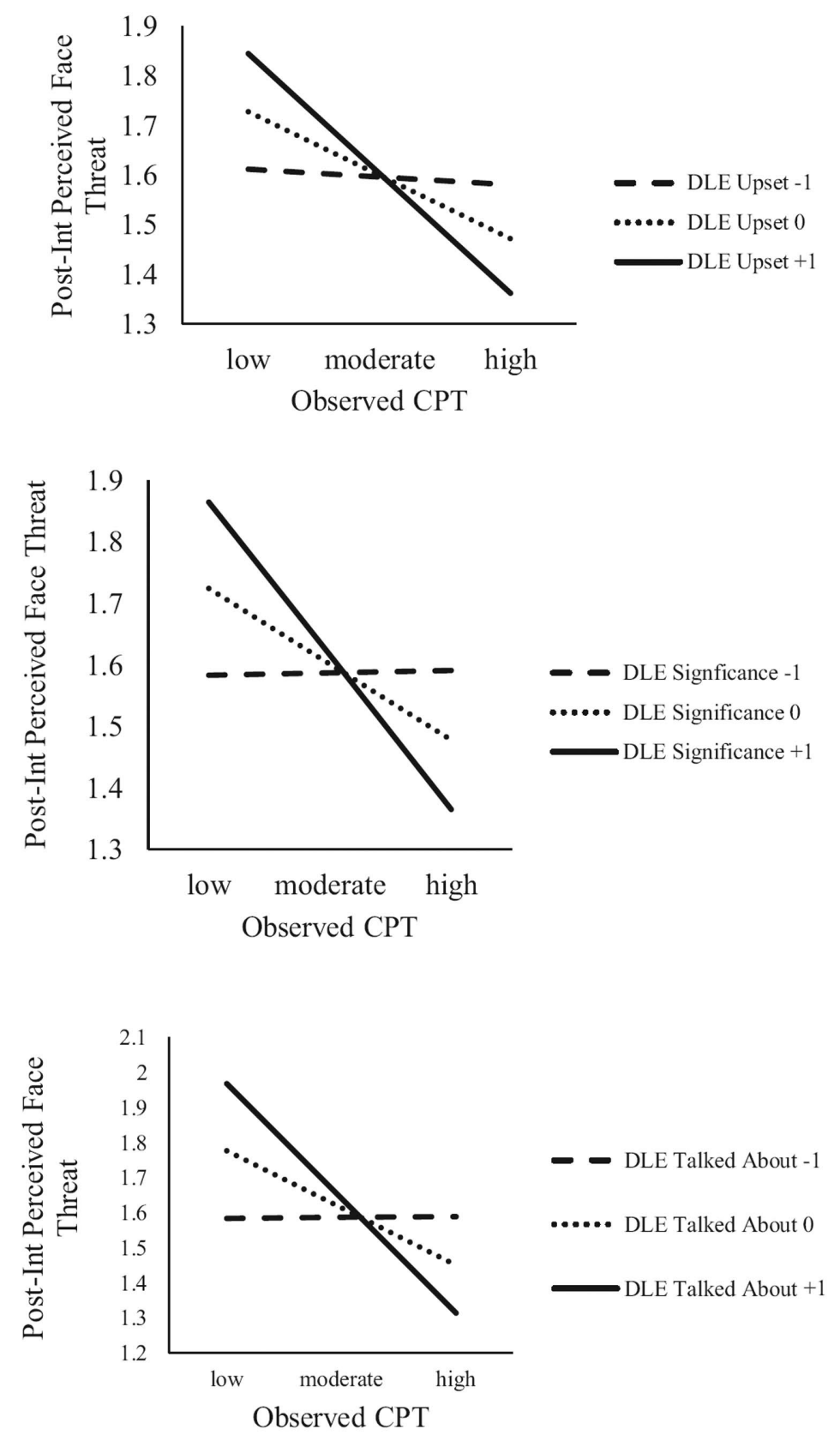

Figure 1. Perceived face threat for observed CPT with perceptions of story topic at moderators

tellers' reports of perceived face threats following the interaction. This was particularly true for people who perceived their story topic as highly significant, upsetting, and for those who had told the story more times. Thus, at high and moderate levels of teller-reported story significance, level of upset, and times told, the stronger the negative relationships between CPTRS and 

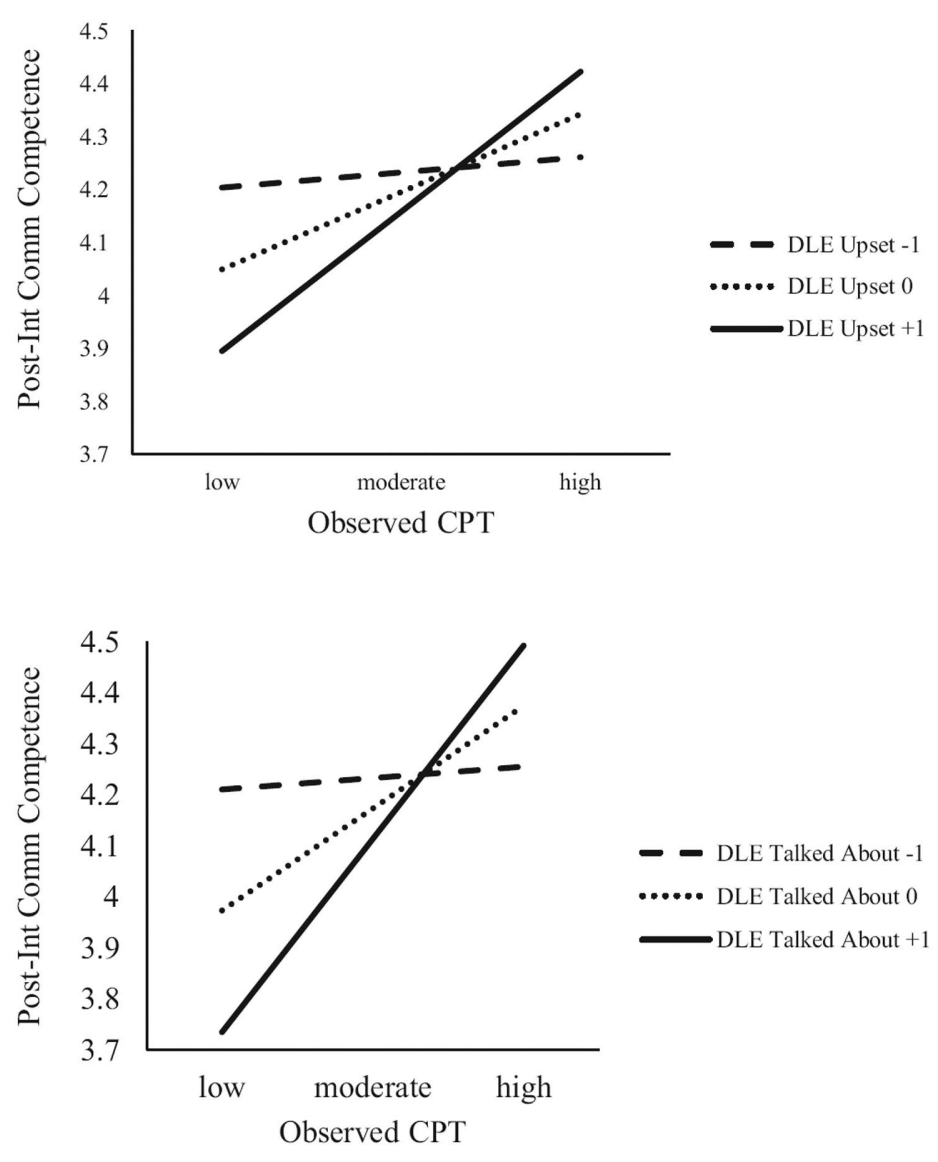

Figure 2. Friends' communication competence for observed CPT with perceptions of story as moderators.

perceived face threat. In other words, it appears that the more significant the incident, the more upsetting, and the more it has been talked about, the more observed CPT mattered to diminishing levels of perceived face threat.

Similar trends that approached significance were found for perceptions of friends' communication competence. Specifically, the more a story had been told ${ }^{2}$ and the more upsetting it was, ${ }^{3}$ the stronger the relationship between observed CPT and tellers' perceptions of their friends' communication competence (see Figure 2).

\section{Discussion}

The current study set out to understand CPT as a form of storylistening and test CNSM theory's proposition 5 that higher levels of CPT should positively predict individual and relational well-being in the context of interpersonal 
storytelling about difficulty. Results confirmed the positive relationship between observed CPT and friends' assessment of the listeners' communication behavior. Observed CPT during a storytelling interaction was significantly positively related to tellers' perceptions of their friends' communication competence, CPT, and negatively related to their friends' perceived face threatening behaviors immediately following the interaction. The majority of research on CPT to date has assessed its effects on relational satisfaction and individual psychosocial health. The current study provides one of the first tests of the communicative evaluations of CPT thereby further establishing CPT as a communication process that matters across evaluative measures during interpersonal interactions and suggesting possible expansion of the outcomes tested in CNSM Theory from individual and relational health (e.g., mental health, relational satisfaction) to assessments of the quality of communication.

Because CPT is both a form of listening that emphasizes verbal and nonverbal attentiveness and understanding and a form of collaborative meaning-making that enables interactional sense-making, it may represent a form of storylistening at the intersections of person-centered communication (Burleson, 1994), active (Bodie et al., 2015), active empathic (Bodie, 2011), and compassionate, other-centered, dialogic listening (see Rehling, 2008; Stewart, 2014). The CPTRS provides a parsimonious way to operationalize both verbal and nonverbal behaviors that represent an other-centered focus. Interestingly, the aspects of the CPTRS that most strongly related to perceptions of listeners' communication skills were validating partner identity, agreement, and affective tone. This may suggest that more than behaviors such as nonverbal immediacy and sharing the floor, validating identity and engaging in confirming behaviors were the most important factors in predicting higher regard for friends' communication skill. Research on confirmation theory (see Dailey, 2006) asserts that our most fundamental human need is the confirmation of our identity and the feeling of being understood. Further, the nature of telling a DLE could contribute to this significance, as identity validation is likely more important when discussing a DLE rather than discussing a happy or funny story. Storytellers must determine the tellability of their story as they navigate attempts to increase intimacy by disclosing about DLE's while also protecting their vulnerability. It is within these boundaries that storytellers construct their identities, necessitating validation of that identity by the storylistener (Norrick, 2005). Notably, some of these CPTRS dimensions overlap with message features constituted by person centered communication (see High \& Dillard, 2012). Future research should continue to tease out overlap and distinctions between these constructs. Ultimately, the current study further supports the importance of the verbal and nonverbal behaviors used to validate not only someone's point of view, but also his or her sense of self in the process. 
Interestingly, although observational (see Koenig Kellas et al., 2010) and other-report (see Horstman \& Holman, 2017) CPT have been empirically related to psychosocial health in previous research, observed CPT was not related to mental health, life satisfaction, positive or negative affect in the current study. It may be that in contexts like stories of marital stress, CPT serves as a proxy for more gestalt patterns of marital interaction and marital health which is also often linked to individual health (see Koenig Kellas et al., 2010). During conversations between friends, however, the same level of relational history may not exist and CPT may not be as consequential or tied to individual well-being. Friendships in the current study were moderately close, but the stories were not about shared stressors nor had they been shared together as in previous studies of marital and family communication (see Trees \& Koenig Kellas, 2009). Future research should further test the relational and conversational contexts in which CPT positively relates to psychosocial well-being and the potential longitudinal effects of CPT patterns within those relationships.

It may also be that the mental health variables chosen in the current study were too global and that more proximal measures-such as perceptions of friends' behavior - represent more appropriate markers of evaluation. Finally, CPT might not have been related to mental health variables in the current study because friends told stories about problems that varied considerably in seriousness and impact. Thus, unlike expressive writing studies in which participants are asked to write about their most traumatic life events (see Neiderhoffer \& Pennebaker, 2009), participants in the current study talked about things that were less serious-or talked about them in ways that avoided deep disclosure based on the constraints of the experimental setting-making the effects on well-being less likely.

We did measure and test the degree to which tellers' perception of the story topic may have moderated the relationship between observed CPT and the more proximal assessments of friends' communication skills. We found that the negative relationship between observed CPT and perceived face threat, in particular, was strongest when tellers saw the stories as more upsetting, significant, and had told them more often. In other words, CPT's ability to temper feelings of face threat seemed to matter most when the story really troubled the teller. A similar trend emerged for perceptions of the friend's communication competence. These findings suggest the need for future research in the context of CNSM theory on the contextual and topical features that help to explain the benefits of CPT. The current findings might also suggest that storytelling interventions would be more useful when tellers have had the opportunity to tell the story previously and not expose tellers to "cold storytelling" since tellers' infrequently told stories do not seem to benefit relationally from observed CPT in the same way as those who have told the story more often. In short, the results suggest 
potential avenues for translational storytelling interventions (Koenig Kellas, 2018) that employ CPT techniques in the context of upsetting and significant but previously told stories.

Like all studies the current investigation must be interpreted in light of its limitations. First, our sample was relatively small which likely resulted in power insufficiencies. According to a post-hoc power analysis a sufficient sample size to confidently reject the null hypotheses in this study would require 44 dyads (see Cohen, 1988; Freidman, 1982). Because we only had 37 dyads in the treatment group from Koenig Kellas et al.'s (2015) study, power may have been limited. To compensate for this, we chose to report trends in the data $(p<.10)$ in addition to our significant findings in order to avoid making Type II errors. Future research with larger samples will be necessary to further assess the effects of CPT on perceptions of friends' communication skills.

The current study was also limited by homogeneity in race, ethnicity, and age and the variety of topics and friend-pair compositions that characterized interactions. Despite these, the current study offers insight into CPT as a potentially effective and compassionate form of storylistening. CPT seems particularly important to positive evaluations of friends' storylistening, especially when the story was upsetting, significant, resolvable, and told. Future research should investigate the links between CPT and compassion and test the impact of storytelling/storylistening interventions that enable CPT, mutual meaning-making, and coping among participants facing difficult narrative sense-making.

Authors' note - A previous version of this manuscript was presented to the Interpersonal Communication Division at the National Communication Association annual convention in Salt Lake City, Utah in November 2018. Mackensie Minniear is also affiliated with University of Georgia.

Funding - The authors received no financial support for the research, authorship, and/or publication of this article.

Open research statement - As part of IARR's encouragement of open research practices, the authors have provided the following information: This research was not pre-registered. The data used in the research are not available. As part of IRB approval, participants were assured that the data would remain confidential and anonymous, therefore the data will remain private, however any questions about the data can be emailed to jkellas2@unl.edu and will be answered in alignment with our approved IRB protocols. 


\section{Notes}

1. Due to the exploratory nature of these analyses, only significant and trending models are reported. Complete results available upon request from the authors.

2. This added $8 \%(F=3.43, p=.07)$ explained variance to the model. Simple slopes were computed using PROCESS (Model 1, Hayes, 2013) when DLE upset was one standard deviation above or below the mean $(M=4.22, S D=1.90)$. Findings show that when the amount of times the story had been told was high and moderate, the strength of the positive relationship between observed CPT and perceptions of the friends' communication competence was higher $(-1 S D=.04$, $p>.05, M=.36, p=.01,+1 S D=.68, p<.01$ ) (see Figure 2 ).

3. This added $9 \%(F=3.24, p=.08)$ explained variance to the model. Simple slopes were created using PROCESS (Model 1, Hayes, 2013) when DLE upset was one standard deviation above or below the mean $(M=5.92, S D=2.36)$. Findings show that when DLE upset was high, the strength of the positive relationship between observed CPT and perceptions of the friends' communication competence was higher $(-1 S D=.06, \mathrm{p}>.05, \mathrm{M}=.29, \mathrm{p}=.06,+1 S D=.52, \mathrm{p}=.01)$ (see Figure 2).

\section{References}

Afifi, T., Afifi, W., Merrill, A. F., Denes, A., \& Davis, S. (2013). "You need to stop talking about this!": Verbal rumination and the costs of social support: Verbal rumination and social support. Human Communication Research, 39(4), 395421. https://doi.org/10.1111/hcre.12012

Bodie, G. D. (2011). The active-empathic listening scale (AELS): Conceptualization and evidence of validity within the interpersonal domain. Communication Quarterly, 59(3), 277-295. https://doi.org/10.1080/01463373.2011.583495

Bodie, G. D., \& Jones, S. M. (2012). The nature of supportive listening II: The role of verbal person centeredness and nonverbal immediacy. Western Journal of Communication, 76(3), 250-269. https://doi.org/10.1080/10570314.2011.6512 $\underline{55}$

Bodie, G. D., Vickery, A. J., Cannava, K., \& Jones, S. M. (2015). The role of "active listening" in informal helping conversations: Impact on perceptions of listener helpfulness, sensitivity, and supportiveness and discloser emotional improvement. Western Journal of Communication, 79(2), 151-173. https://doi. org/10.1080/10570314.2014.943429

Burleson, B. R. (1994). Comforting messages: Features, functions, and outcomes. In J. A. Daly \& J. M. Wiemann (Eds.), Strategic interpersonal communication (pp. 135-161). Erlbaum. Cohen, J. (1988). Statistical power analysis for the behavioral sciences (2nd ed.). Routledge Academic.

Cupach, W. R., \& Carson, C. L. (2002). Characteristics and consequences of interpersonal complaints associated with perceived face threat. Journal of Social and Personal Relationships, 19(4), 443-462. https://doi.org/10.1177/0265 $\underline{407502019004047}$ 
Dailey, R. M. (2006). Confirmation in parent-adolescent relationships and adolescent openness: Toward extending confirmation theory. Communication Monographs, 73(4), 434-458. https://doi.org/10.1080/03637750601055432

Deiner, E., Emmons, R. A., Larsen, R. J., \& Griffin, S. (1985). The satisfaction with life scale. Journal of Personality Assessment, 49(1), 71-75. https://doi.org/10.1207/ s15327752jpa4901_13

Delia, J., O'Keefe, B. J., \& O'Keefe, D. (1982). The constructivist approach to communication. In F. E. X. Dance (Ed.), Human communication theory (pp. 147191). Harper \& Row.

Frattaroli, J. (2006). Experimental disclosure and its moderators: A meta-analysis. Psychological Bulletin, 132(6), 823-865. https://doi. org/10.1037/0033-2909.132.6.823

Freidman, H. (1982). Simplified determinations of statistical power, magnitude of effect and research sample sizes. Educational and Psychological Measurement, 42(2), 521-526. https://doi.org/10.1177/001316448204200214

Guerrero, L. K. (1994). "I'm so mad I could scream": The effects of anger expression on relational satisfaction and communication competence. Southern Communication Journal, 59(2), 125-141. https://doi. org/10.1080/10417949409372931

Hayes, A. F. (2013). An introduction to mediation, moderation, and conditional process analysis. Guilford Press.

High, A. C., \& Dillard, J. P. (2012). A review and meta-analysis of person-centered messages and social support outcomes. Communication Studies, 63(1), 99-118. https://doi.org/10.1080/10510974.2011.598208

High, A. C., \& Solomon, D. H. (2016). Explaining the durable effects of verbal person-centered supportive communication: Indirect effects or invisible support? Human Communication Research, 42(2), 200-221. https://doi. org/10.1111/hcre.12077

Horstman, H. K., \& Holman, A. (2017). Communicated sense-making after miscarriage: A dyadic analysis of spousal communicated perspective-taking, well-being, and parenting role salience. Health Communication, 33(10), 13171326. https://doi.org/10.1080/10410236. 2017.1351852

Horstman, H. K., Maliski, R., Hays, A., Cox, J., Enderle, A., \& Nelson, L. R. (2016). Unfolding narrative meaning over time: The contributions of mother-daughter conversations of difficulty on daughter narrative sense-making and well-being. Communication Monographs, 83(3), 326-348. https://doi.org/10.1080/0363775 1.2015 .1068945

Jones, S. M., \& Guerrero, L. K. (2001). The effects of nonverbal immediacy and verbal person centeredness in the emotional support process.

Human Communication Research, 27(4), 567-596. https://doi. org/10.1111/j.1468-2958.2001.tb00793.x

Joseph, A., Afifi, T. D., \& Denes, A. (2016). (Unmet) standards for emotional support and their short- and medium-term consequences. Communication Monographs, 83(2), 163-193. https://doi.org/10.1080/03637751.2015.1068432 
Koenig Kellas, J. (2018). Communicated narrative sense-making theory: Linking storytelling and well-being (pp. 62-74). In D. O. Braithwaite, E. A. Suter, \& K. Floyd (Eds.), Engaging theories in family communication: Multiple perspectives. SAGE.

Koenig Kellas, J., Carr, K., Kranstuber Horstman, H., \& DiLillo, D., (2017). The communicated perspective-taking rating system and links to well-being in marital conflict. Personal Relationships, 24(1), 185-202. https://doi.org/10.1111/ pere. 12177

Koenig Kellas, J., \& Kranstuber Horstman, H. (2015). Communicated narrative sense-making: Understanding family narratives, storytelling, and the construction of meaning through a communicative lens. In L. Turner \& R. West (Eds.), Sage handbook of family communication (pp. 76-90). SAGE.

Koenig Kellas, J., Kranstuber Horstman, H., Willer, E. K., \& Carr, K. (2015) The benefits and risks of telling and listening to stories of difficulty over time: Experimentally testing the expressive writing paradigm in the context of interpersonal communication between friends. Health Communication, 30(9), 843-858. https://doi.org/10.1080/10410236.2013.850017

Koenig Kellas, J., \& Trees, A. (2013). Family stories and storytelling: Windows into the family soul. In A. L. Vangelisti (Ed.), The Routledge handbook of family communication (2nd ed., pp. 391-406). Routledge.

Koenig Kellas, J., \& Trees, A. R. (2005). Rating interactional sense-making in the process of joint storytelling. In V. Manusov (Ed.), The sourcebook of nonverbal measures: Going beyond words (pp. 281-294). Erlbaum.

Koenig Kellas, J., Trees, A. R., Schrodt, P., LeClair-Underberg, C., \& Willer, E. K. (2010). Exploring links between well-being and interactional sense-making in married couples' jointly told stories of stress. Journal of Family Communication, 10(3), 174-193. https://doi.org/10.1080/15267431.2010.489217

Koenig Kellas, J., Willer, E. W., \& Trees, A. R. (2013). Communicated perspectivetaking during stories of marital stress: Spouses' perceptions of one another's perspective-taking behaviors. Southern Communication Journal, 78(4), 326351. https://doi.org/10.1080/1041794X.2013.815264

Kranstuber, H., \& Koenig Kellas, J. (2011). "Instead of growing under her heart, I grew in it": The relationship between adoption entrance narratives and adult adoptees' self-concept. Communication Quarterly, 59(2), 179-199. https://doi. org/10.1080/01463373.2011.563440

Lyubomirsky, S., Sousa, L., \& Dickerhoof, R. (2006). The costs and benefits of writing, talking, and thinking about life's triumphs and defeats. Journal of Personal and Social Psychology, 90(4), 692-708. https://doi. org/10.1037/0022-3514.90.4.692

Niederhoffer, K. G., \& Pennebaker, J. W. (2009). Sharing one's story: On the benefits of writing or talking about emotional experience. In C. R. Snyder \& S. J. Lopez (Eds.), Oxford handbook of positive psychology (pp. 621-632). Oxford University Press.

Norrick, N. R. (2005). The dark side of tellability. Narrative Inquiry, 15(2), 323-343. https://doi.org/10.1075/ni.15.2.07nor 
Pennebaker, J. W. (1989). Confession, inhibition, and disease. In L. Berkowitz (Ed.), Advances in experimental social psychology (Vol. 22., pp. 211-244). Academic Press. https://doi.org/10.1016/S0065-2601(08)60309-3

Pennebaker, J. W., \& Graybeal, A. (2001). Patterns of natural language use: Disclosure, personality, and social integration. Current Directions in Psychological Science, 10(3), 90-93. https://doi.org/10.1111/1467-8721.00123

Rehling, D. L. (2008). Compassionate listening: A framework for listening to the seriously ill. The International Journal of Listening, 22(1), 83-89. https://doi. org/10.1080/10904010701808516

Rimé, B., Philippot, P., Boca, S., \& Mesquita, B. (1992). Long-lasting cognitive and social consequences of emotion: Social sharing and rumination. European Review of Social Psychology, 3(1), 225-258. https://doi. org/10.1080/14792779243000078

Spitzberg, B. H. (1994). The dark side of (in)competence. In W. R. Cupach \& B. H. Spitzberg (Eds.), The dark side of interpersonal communication (pp. 25-50). Lawrence Erlbaum.

Stewart, J. (2014). U\&Me: Communicating in moments that matter. Taos Instituted Publications.

Stewart, A. L., Hays, R. D., \& Ware, J. E., Jr. (1992). Measuring functioning and wellbeing: The medical outcomes study approach. Duke University Press.

Stewart, J., \& Koenig Kellas, J. (2020). Co-constructing uniqueness: An interpersonal process promoting dialogue. Atlantic Journal of Communication, 28(1), 5-21. https://doi.org/10.1080/15456870.2020.1684289

Stiles, W. B. (1987). "I have to talk to somebody": A fever model of disclosure. In V. J. Derelega \& J. H. Berg (Eds.), Self-disclosure: Theory, research, and therapy (pp. 257-282). Plenum Press.

Stiles, W. B., Shuster, P. L., \& Harrigan, J. A. (1992). Disclosure and anxiety: A test of the fever model. Journal of Personality and Social Psychology, 63(6), 980-988. https://doi.org/10.1037/0022-3514.63.6.980

Trees, A. R., \& Koenig Kellas, J. (2009). Telling tales: Enacting family relationships in joint storytelling about difficult family experiences. Western Journal of Communication, 73(1), 91-111. https://doi.org/10.1080/10570310802635021

Watson, D., Clark, L. A., \& Tellegen, A. (1988). Development and validation of brief measures of positive and negative affect: The PANAS scales. Journal of Personality \& Social Psychology, 54(6), 1063-1070. https://doi. org/10.1037/0022-3514.54.6.1063

Weber, A. L., Harvey, J. H., \& Stanley, M. A. (1987). The nature and motivations of accounts for failed relationships. In R. Burnett, P. McGhee, \& D. D. Clarke (Eds.), Accounting for relationships: Explanation, representation, and knowledge (pp. 114-133). Methuen 